\title{
Combination of Suspension Array and Mycelial Growth Assay for Detecting Multiple-Fungicide Resistance in Botrytis cinerea in Hebei Province in China
}

\author{
Zehua Su, ${ }^{1}$ Xin Zhang, ${ }^{1,2, \dagger}$ Jianjiang Zhao, ${ }^{3}$ Wenqiao Wang, ${ }^{3}$ Lei Shang, ${ }^{1}$ Shengnan Ma, ${ }^{1}$ Yao Mawulikplimi Adzavon, \\ Fen Lu, ${ }^{3}$ Mantian Weng, ${ }^{1}$ Xiuying Han, ${ }^{3}$ Lei Yang, ${ }^{1}$ Qinghui Zhao, ${ }^{1}$ Pengxiang Zhao, ${ }^{1}$ Fei Xie, ${ }^{1}$ and Xuemei Ma ${ }^{1, \dagger}$ \\ ${ }^{1}$ College of Life Science and Bio-engineering, Beijing University of Technology, Beijing 100124, China; ${ }^{2}$ College of Applied \\ Sciences, Beijing University of Technology, Beijing 100124, China; and ${ }^{3}$ Plant Protection Institute, Hebei Academy of Agricul- \\ tural and Forestry Sciences, Baoding 071000, China
}

\begin{abstract}
To provide a high-throughput, efficient, and accurate method to monitor multiple-fungicide resistance of Botrytis cinerea in the field, we used the suspension array, sequencing, and mycelial growth assay in our research. Discriminating-dose bioassays for detecting carbendazim, diethofencarb, boscalid, and iprodione resistance $\left(\mathrm{Car}^{\mathrm{R}}, \mathrm{Die}^{\mathrm{R}}, \mathrm{Bos}^{\mathrm{R}}\right.$, and $\mathrm{Ipr}^{\mathrm{R}}$, respectively) were used to analyze 257 isolates collected from Hebei Province in China during 2016 and 2017. High resistance frequencies to carbendazim $(100 \%)$, diethofencarb $(92.08 \%)$, and iprodione $(86.59 \%)$ were detected. Bos ${ }^{\mathrm{R}}$ isolates accounted for $11.67 \%$ of the total. In addition, 103 isolates were randomly selected for phenotype and genotype detection. The high-throughput suspension array was utilized to detect eight genotypes simultaneously, including BenA-E198, BenA-198A, SdhBH272, SdhB-272Y, BcOS1-I365, BcOS1-365S, erg27-F412, and erg27-412S, which were associated with resistance toward carbendazim or diethofencarb, boscalid, iprodione, and fenhexamid $\left(\mathrm{Fen}^{\mathrm{R}}\right)$, respectively. Most of the benzimidazole-resistant isolates $(81.55 \%)$ possessed the E198V mutation in the BenA gene. Ninety-three isolates with dual

resistance to carbendazim and diethofencarb showed the E198V/K mutation. All Bos ${ }^{\mathrm{R}}$ isolates carried the H272R mutation in the $S d h B$ gene. The I365S and Q369P+N373S (66.99\%) mutations in the BcOS1 gene were more frequently observed. No mutation was detected in the erg 27 gene in Hebei isolates. There were 13 resistance profile phenotypes. Phenotypes with triple resistance were the most common $(83.50 \%)$, and $\mathrm{Car}^{\mathrm{R}} \mathrm{Die}^{\mathrm{R}} \mathrm{Bos}^{\mathrm{S}} \mathrm{Ipr}^{\mathrm{R}} \mathrm{Fen}{ }^{\mathrm{S}}$ was the major type. $\mathrm{Car}^{\mathrm{R}}$ isolates that carried E198V/K/A were all highly resistant (HR) and only one F200Y mutant was moderately resistant (MR) to carbendazim. Isolates that possessed E198V/K were MR or HR to diethofencarb. Bos ${ }^{R}$ isolates that possessed $\mathrm{H} 272 \mathrm{R}$ mutation were lowly resistant (LR). $\mathrm{Ipr}^{\mathrm{R}}$ isolates were all LR or MR. The distribution of half maximal effective concentrations of $\mathrm{Car}^{\mathrm{R}}$ isolates with $\mathrm{E} 198 \mathrm{~V} / \mathrm{K}$ mutations and $\mathrm{Ipr}^{\mathrm{R}}$ isolates with Q369P+ N373S mutations significantly increased from 2016 to 2017. Combined with our observations, a combination method of the high-throughput suspension array and the mycelial growth assay was suggested to accurately monitor multiple resistance of $B$. cinerea in the field.
\end{abstract}

Gray mold caused by the plant pathogen Botrytis cinerea is a destructive and ubiquitous disease. The control of gray mold mainly depends on using different chemical fungicides. However, the high rate of reproduction and genetic variation of $B$. cinerea, along with the abuse of fungicides, has resulted in increasing resistance of B. cinerea worldwide (De Miccolis Angelini et al. 2014b; Saito et al. 2016).

There are eight major categories of fungicides for controlling $B$. cinerea, including benzimidazoles, $N$-phenylcarbamates, dicarboximides (DCs), anilinopyrimidines (APs), phenylpyrroles, quinone outside inhibitors (QoIs), succinate dehydrogenase inhibitors (SDHIs), and sterol biosynthesis inhibitors (SBIs). Both benzimidazoles and $\mathrm{N}$-phenylcarbamates inhibit the growth of mycelial and spore germ tubes by binding to the $\beta$-tubulin protein in fungi. Therefore, E198A, E198V, E198K, and F200Y mutations in the $\beta$-tubulin gene $(B e n A)$ will greatly reduce the effect of benzimidazoles on B. cinerea (Banno et al. 2008; Luck and Gillings 1995; Yarden and Katan 1993). Meanwhile, pathogens with the same mutations of E198V and E198K are resistant to $N$-phenylcarbamates (Beever

${ }^{\dagger}$ Corresponding authors: X. Zhang; zxin@bjut.edu.cn, and X. Ma; xmma@bjut.edu.cn

\section{Z. Su, X. Zhang, and J. Zhao contributed equally to this work.}

Funding: This work was funded by the Beijing Postdoctoral Research Foundation (grant 2017-ZZ-019) and the Special Fund for Agro-scientific Research in the Public Interest (grant 201303023).

The author(s) declare no conflict of interest.

Accepted for publication 5 January 2019

(C) 2019 The American Phytopathological Society et al. 1989; Yourman et al. 2000; Ziogas et al. 2009). Research suggests that dicarboximides interfere with the osmotic signal transduction pathway. The amino acid substitutions in the osmosensing histidine kinase gene $(B c O S 1)$ were I365S, I365N, I365R, and Q369P+N373S (Cui et al. 2002, 2004; Grabke et al. 2014; Ma et al. 2007; Oshima et al. 2006). APs can be used to control benzimidazoles, $\mathrm{N}$-phenylcarbamates, and DC-resistant isolates of $\mathrm{B}$. cinerea because there is no cross-resistance with these fungicides (Latorre et al. 2002). Phenylpyrroles constitute a new type of fungicide, and existing theory suggests that they are associated with overactivation of mitogen-activated protein kinases (Bartlett et al. 2002). The fungicidal effects of QoIs and cytochrome b (Cytb) are closely related (Yoshimi et al. 2005). Mutations in key sites of the Cytb gene, such as the G143A mutation, result in fungicide resistance (Ishii et al. 2009; Jiang et al. 2009; Leroch et al. 2013). SDHIs can prevent a variety of diseases, act primarily on the mitochondrial respiratory chain, and interact with the succinate dehydrogenase complex. Resistance to SDHIs occurs after the substitution of P225T/F/L, N230I, and $\mathrm{H} 272 \mathrm{Y} / \mathrm{R} / \mathrm{L}$ in the succinate dehydrogenase iron sulfide gene $(S d h B)$ (Veloukas et al. 2011; Yin et al. 2011). SBIs restrain fungal growth by inhibiting the synthesis of different enzymes during sterol synthesis. However, 3-ketoreductase (erg27) mutant strains that exhibit F412S/I/V mutations are resistant to SBIs (Debieu et al. 2013).

Compared with conventional methods, molecular detection methods are simpler, more sensitive, and efficient. These molecular methods include sequencing (Fillinger et al. 2012; Leroux et al. 2010), cleaved amplified polymorphic sequence (De Miccolis Angelini et al. 2014b), polymerase chain reaction (PCR) restriction fragment length polymorphism (Ishii et al. 2009; Van der Heyden et al. 2014), allele-specific PCR (De Miccolis Angelini et al., 2012, 2014a; Yin et al. 2012), tetra-primer amplification refractory mutation systems PCR (Muñoz et al. 2009), real-time PCR (Banno et al. 2008; Billard et al. 2012), and high-resolution melting analysis (Chatzidimopoulos et al. 2014). However, the majority of these methods are associated 
with some drawbacks. Their greatest weakness is that they can only detect a single codon of a single sample in turn. They are thus not suitable for large-scale resistance detection in B. cinerea. A simple and highthroughput assay for detecting fungicide resistance is required for large-scale monitoring of the resistant isolates of $B$. cinerea. The multiple detection method of the suspension array could simultaneously detect eight genotypes in four target genes (BenA, SdhB, BcOS1, and erg27) of $B$. cinerea that are associated with resistance to five fungicides (benzimidazoles or $N$-phenylcarbamates, DCs, SBIs, and SDHIs; Zhang et al. 2016). The eight genotypes included BenAE198 (GAG), BenA-198A (GCG), SdhB-H272 (CAC), SdhB-272Y (TAC), BcOS1-I365 (ATC), BcOS1-365S (AGC), erg27-F412 (TTC), and erg27-412S (TCC).

In this study, we aimed to provide a flexible, high-throughput, and accurate method to obtain early warnings and monitor the fungicide resistance of $B$. cinerea isolates, which could provide the basis for selecting effective fungicides for controlling gray mold in the field.

\section{Materials and Methods}

Isolation of B. cinerea strains. A total of 257 single spore isolates from B. cinerea strains collected from tomato in Baoding, Cangzhou, Handan, Hengshui, Langfang, Qinhuangdao, Shijiazhuang, Tangshan, and Xingtai in Hebei Province in China were used in this study (Table 1).

DNA extraction. The isolates were cultured on potato dextrose agar (PDA) medium at $22^{\circ} \mathrm{C}$ in the dark for 14 days before DNA extraction. Mycelia were collected and frozen in liquid nitrogen, and the genomic DNA of B. cinerea was extracted with an Ezup Column Fungi Genomic DNA extraction kit (Sangon Biotech Co., Ltd., Shanghai, China). The DNA concentration was measured with a NanoDrop 1000 spectrometer (Thermo Scientific). All genomic DNA was diluted to $10 \mathrm{ng} / \mu \mathrm{l}$ for the subsequent experiment and was stored at $-20^{\circ} \mathrm{C}$ until use.

Suspension array. The method of suspension array used here was reported by Zhang et al. (2016), including multiplex PCR, multiplex allele-specific primer extension (ASPE) PCR, hybridization, and detection. These steps were designed for amplifying target sequences of isolates in four fungicide resistance-associated genes (BenA, SdhB, BcOS1, and erg27) and attaching them to TAG labels. These products with TAG hybridized to specific microspheres with anti-TAG sequences. Genotypes of these isolates were analyzed with the Bio-Plex 200 system (Bio-Rad). The details are described below.

Multiplex PCR. Four DNA fragments of the target regions (BenA, $S d h B, B c O S 1$, and erg27) were amplified simultaneously in one reaction. PCR reactions were conducted in a $25 \mu \mathrm{l}$ reaction volume containing $10 \mathrm{ng}$ of the isolate genomic DNA template, $1 \times$ PCR reaction buffer $\left(-\mathrm{Mg}^{2+}\right), 1.5 \mathrm{mM}$ of $\mathrm{MgCl}_{2}, 2 \mathrm{U}$ of Platinum Taq DNA polymerase (Invitrogen), $0.2 \mathrm{mM}$ of deoxy-nucleoside triphosphate (dNTP; TaKaRa), $0.05 \mu \mathrm{M}$ of each BenA primer, $0.4 \mu \mathrm{M}$ of each $S d h B$ primer, and $0.2 \mu \mathrm{M}$ of the other primers. The amplification conditions were as follows: $5 \mathrm{~min}$ at $94^{\circ} \mathrm{C}$; followed by 35 cycles of $30 \mathrm{~s}$ at $94^{\circ} \mathrm{C}, 30 \mathrm{~s}$ at $54^{\circ} \mathrm{C}$ and $30 \mathrm{~s}$ at $72^{\circ} \mathrm{C}$; with a final extension at $72^{\circ} \mathrm{C}$ for $10 \mathrm{~min}$. ExoSAP-IT (Affymetrix) was used to remove the unused primers and nucleotides and the PCR product was kept at $4{ }^{\circ} \mathrm{C}$ until use. The primers used in multiplex PCR are detailed in Table 2.

Table 1. Botrytis cinerea isolates used in the study

\begin{tabular}{lcc}
\hline & \multicolumn{2}{c}{ Number of isolates } \\
\cline { 2 - 3 } Origin & $\mathbf{2 0 1 6}(\boldsymbol{n}=\mathbf{8 4})$ & $\mathbf{2 0 1 7}(\boldsymbol{n}=\mathbf{1 7 3})$ \\
\hline Baoding & 24 & 58 \\
Cangzhou & 9 & 0 \\
Handan & 2 & 12 \\
Hengshui & 2 & 2 \\
Langfang & 6 & 20 \\
Qinhuangdao & 13 & 8 \\
Shijiazhuang & 15 & 43 \\
Tangshan & 10 & 19 \\
Xingtai & 3 & 11 \\
\hline
\end{tabular}

Multiplex ASPE PCR. ASPE PCR was performed by coupling different TAG sequences to specific target genes of the ExoSAPIT-treated PCR product. ASPE reactions were done in a final $20 \mu \mathrm{l}$ volume containing $1 \mu \mathrm{l}$ of $1 \times$ PCR reaction buffer $\left(-\mathrm{Mg}^{2+}\right), 1.25 \mathrm{mM}$ of $\mathrm{MgCl}_{2}, 0.75 \mathrm{U}$ of Platinum Tsp DNA polymerase (Invitrogen), $25 \mathrm{nM}$ of each TAG-ASPE primer, $5 \mu \mathrm{M}$ of deoxyadenosine triphosphate (dATP), $5 \mu \mathrm{M}$ of deoxythymidine triphosphate (dTTP), $5 \mu \mathrm{M}$ of deoxyguanosine triphosphate (dGTP), and $5 \mu \mathrm{M}$ of biotin-deoxycytidine diphosphate (biotin-dCTP; Invitrogen). Reaction mixtures were preheated for $2 \mathrm{~min}$ at $96^{\circ} \mathrm{C}$; followed by 30 cycles at $94^{\circ} \mathrm{C}$ for $30 \mathrm{~s}$, $55^{\circ} \mathrm{C}$ for $1 \mathrm{~min}$, and $37^{\circ} \mathrm{C}$ for $2 \mathrm{~min}$; with a final hold at $4^{\circ} \mathrm{C}$ until use. The primers used in multiplex ASPE PCR are detailed in Table 3.

Hybridization to MagPlex-TAG microspheres and detection. Fragments with the TAG sequence were hybridized with the MagPlex-TAG microspheres (Luminex, U.S.A.). The hybridization reaction was performed in a total volume of $50 \mu$ l containing 2,500 of each MagPlex-TAG microsphere, $5 \mu$ of ASPE reaction product, $0.4 \mathrm{M}$ of $\mathrm{NaCl}, 0.2 \mathrm{M}$ of Tris, and $0.16 \%$ Triton $\mathrm{X}-100, \mathrm{pH}$ 8.0. These mixtures were denatured at $95^{\circ} \mathrm{C}$ for $90 \mathrm{~s}$ and incubated at $37^{\circ} \mathrm{C}$ for $1 \mathrm{~h}$. After incubation, samples were filtered through 1.2$\mu \mathrm{m}$ MultiScreen HTS-BV 96-well filtration plates (Merck Millipore) and washed twice with $75 \mu \mathrm{l}$ of $1 \times \mathrm{Tm}$ hybridization buffer $(0.2 \mathrm{M}$ of $\mathrm{NaCl}, 0.1 \mathrm{M}$ of Tris, and $0.08 \%$ of Triton X-100, $\mathrm{pH} 8.0$ ). Microspheres with target DNA were then resuspended in $120 \mu \mathrm{l}$ of $1 \times \mathrm{Tm} \mathrm{Hy}-$ bridization Buffer containing $0.1 \%$ bovine serum albumin and $2 \mathrm{mg} / \mathrm{ml}$ streptavidin-R-phycoerythrin (SAPE, Invitrogen), transferred to new 96-well plates (Corning), and incubated at $37^{\circ} \mathrm{C}$ for $15 \mathrm{~min}$. Samples at $50 \mu \mathrm{l}$ were then analyzed at room temperature on the Bio-Plex 200 system. For each sample, the median fluorescence intensity (MFI) of at least 100 beads was analyzed for each bead set.

Fungicides sensitive to carbendazim, diethofencarb, iprodione, and boscalid. Sensitivity of isolates to fungicides was determined by discriminating-dose and mycelial growth assays. Technicalgrade carbendazim (98.3\% active ingredient [a.i.]; Zhuozhou Huatai Fine-Chemical Factory), diethofencarb (95\% a.i.; Shijiazhuang Pesticide Chemicals Factory), boscalid (95\% a.i.; BASF), and iprodione (96.5\% a.i.; Bayer Crop Science) were respectively dissolved in acetone to prepare stock solutions. Concentrations of $1 \mathrm{mg}$ per liter of carbendazim, $5 \mathrm{mg}$ per liter of diethofencarb, $5 \mathrm{mg}$ per liter of iprodione, and $5 \mathrm{mg}$ per liter of boscalid were used as a discriminating dose for the evaluations of the sensitivities of all 257 isolates in a simplified sensitivity test. Moreover, the half maximal effective concentration $\left(\mathrm{EC}_{50}\right)$ values of 103 randomly selected isolates were determined by mycelial growth assays. Fungicides were singularly added to PDA. Media containing serial concentrations of carbendazim $(0,1,5,10,50,100$, and $500 \mathrm{mg}$ per liter $)$, diethofencarb $(0,0.1,0.5,1$, 5,10 , and $50 \mathrm{mg}$ per liter), iprodione $(0,0.4,0.8,1.6,3.2,6.4$, and $12.8 \mathrm{mg}$ per liter), and boscalid $(0.1,0.5,1,5,10,50$, and $100 \mathrm{mg}$ per liter) were prepared. All isolates were precultured on PDA. Mycelial plugs $(6 \mathrm{~mm})$ from the edge of the 3-day-old colony on PDA were transferred to the medium containing fungicides. The orthogonal diameters were measured after 3 days at $25^{\circ} \mathrm{C}$. Three replicates were used for each isolate. The resistance factor (RF) was calculated as the ratio between the $\mathrm{EC}_{50}$ value of the resistant isolate and the mean $\mathrm{EC}_{50}$ value of sensitive isolates (De Miccolis Angelini et al. 2014a). Resistant isolates to carbendazim, diethofencarb, and iprodione were defined as those with an RF $>5$. The resistant isolates were classified as follows: lowly resistant (LR), with $5 \leq \mathrm{RF}<10$; moderately resistant (MR), with $10 \leq \mathrm{RF}<40$; and highly resistant $(\mathrm{HR})$, with $\mathrm{RF} \geq$ 40. In addition, isolates with $R F$ values $<10$ were considered sensitive to boscalid, and isolates were classified as follows: low resistant (LR), with $10 \leq \mathrm{RF}<50$; moderately resistant (MR), with $50 \leq \mathrm{RF}<100$; and highly resistant (HR), with $\mathrm{RF} \geq 100$.

Sequencing. As the standard of molecular detection of $B$. cinerea, sequencing was used to verify all mutations in the four genes in our study. Each pair of primers from multiplex PCR was used to amplify DNA from all 70 isolates of $B$. cinerea. The PCR products were sent to Sangon Biotech for sequencing.

Data analysis. For each allele, a criterion was set as the mean MFI of all blank controls $\pm 5 \mathrm{SD}$. The positive MFI values required to 
meet this criterion determined the genotypes for each allele. The effective concentration of each fungicide that reduced mycelial growth by $50 \%\left(\mathrm{EC}_{50}\right)$ was determined with DPS Data Processing System software.

\section{Results}

Resistance frequency of $\boldsymbol{B}$. cinerea in Hebei Province. To monitor the overall status of fungicide resistance of $B$. cinerea in Hebei Province, a discriminating dose was used to test 257 isolates. The results showed that all isolates were resistant to carbendazim $\left(\mathrm{Car}^{\mathrm{R}}\right)$, and resistance frequencies to diethofencarb $\left(\mathrm{Die}^{\mathrm{R}}\right)$, iprodione $\left(\mathrm{Ipr}^{\mathrm{R}}\right)$, and boscalid $\left(\mathrm{Bos}^{\mathrm{R}}\right)$ were $92.08,86.59$, and $11.67 \%$, respectively.

Detection of mutations using the suspension array. A total of 103 randomly selected $B$. cinerea isolates were genotyped by the Bio-Plex suspension array. The average MFIs of two replicates are shown in Table 4. The signal was considered positive when MFI was greater than the threshold. Otherwise, results with no positive signal in two alleles at one codon indicated that another mutation existed. For example, the genotypes of isolate 14 were BenAE198\# (where the number sign "\#” indicates another mutant genotype), SdhB-H272, BcOS1-I365S, and erg27-F412. The genotypes of these isolates were directly obtained from the MFI value in the suspension array without subsequent analysis. Eight genotypes could be simultaneously detected by the suspension array from only one unit of the DNA template.

Molecular detection in B. cinerea. The results of the suspension array were analyzed and compared with the sequencing data. The results are presented in Table 5 as the amino acid substitutions of the field isolates. According to the sequencing results, the negative signal in the suspension array corresponded to other mutations, such as BenA-E198V, BenA-E198K, and SdhB-H272R. These genotypes were not set in the detection scope of the suspension array. For example, the genotype of isolate 14 in the BenA gene showed neither the wild type nor the E198A mutant, whereas the sequencing results showed that it was E198K at this codon. Therefore, other mutated genotypes of the measured codon in the suspension array did not affect the fungicide resistance decision. Using statistical analysis, the resistance frequency between the suspension array and sequencing was determined (Table 6). The other mutations in the detected codons of the suspension array showed no effect on the resistance frequency of BenA-198, SdhB-272, BcOS1-365, or erg27-412 (99.03, 4.85, 21.36 , and $0 \%$, respectively), and the results of these codons in the suspension array and sequencing were fully consistent. The differences in resistance frequency between the two molecular methods were attributable to mutations in other codons that were not within the detection range of the suspension array, including BenA-200 and $B c O S 1-369+373$. The resistance frequency of the BenA-F200Y and $B c O S 1-\mathrm{Q} 369 \mathrm{P}+\mathrm{N} 373 \mathrm{~S}$ mutations was 0.97 and $54.37 \%$, resulting in 100, 4.85, 75.73, and 0\% resistance frequency in BenA, $S d h \mathrm{~B}$, $B C O S 1$, and $\operatorname{erg} 27$, respectively. The differences in resistance frequency were mainly concentrated in the $B c O S 1$ gene associated with iprodione resistance; according to these results, the genotype of $\mathrm{Q} 369 \mathrm{P}+\mathrm{N} 373 \mathrm{~S}$ accounted for the majority of the resistance.

Multiple-fungicide resistance by molecular detection. According to the genotype results of $B e n A, S d h B, B c O S 1$, and $\operatorname{erg} 27,13$ different genotypes are shown in Table 7. Isolates with multiple-fungicide resistance (up to four) represented the majority of the population $(98.06 \%)$. Isolates with E198K or E198V mutation in BenA were resistant to both carbendazim and diethofencarb. Isolates with dual $\left(\mathrm{Car}^{\mathrm{R}} \mathrm{Die}^{\mathrm{S}} \mathrm{Bos}^{\mathrm{S}} \operatorname{Ipr}^{\mathrm{R}} \mathrm{Fen}^{\mathrm{S}}, \mathrm{Car}^{\mathrm{R}} \mathrm{Die}^{\mathrm{S}} \mathrm{Bos}^{\mathrm{R}} \operatorname{Ipr}^{\mathrm{S}} \mathrm{Fen}^{\mathrm{S}}, \mathrm{Car}^{\mathrm{R}} \operatorname{Die}^{\mathrm{R}} \operatorname{Bos}^{\mathrm{S}} \mathrm{Ipr}^{\mathrm{S}} \mathrm{Fen}{ }^{\mathrm{S}}\right)$, triple $\left(\mathrm{Car}^{\mathrm{R}} \mathrm{Die}^{\mathrm{S}} \mathrm{Bos}^{\mathrm{R}} \operatorname{Ipr}^{\mathrm{R}} \mathrm{Fen}^{\mathrm{S}}, \mathrm{Car}^{\mathrm{R}} \operatorname{Die}^{\mathrm{R}} \operatorname{Bos}^{\mathrm{S}} \operatorname{Ipr}^{\mathrm{R}} \mathrm{Fen}^{\mathrm{S}}\right)$, or quadruple $\left(\mathrm{Car}^{\mathrm{R}} \operatorname{Die}^{\mathrm{R}} \operatorname{Bos}^{\mathrm{R}} \operatorname{Ipr}^{\mathrm{R}} \mathrm{Fen}^{\mathrm{S}}\right)$ fungicide resistance accounted for 13.59, 83.50 , and $0.97 \%$, respectively, and type $X\left(\operatorname{Car}^{R} \operatorname{Die}^{R} \operatorname{Bos}^{S} \operatorname{Ipr}^{R} F e n{ }^{S}\right)$ isolates accounted for the majority. All of the isolates had mutations in BenA conferring carbendazim resistance in field isolates of B. cinerea. For BcOS1, $67.74 \%$ of isolates ( 21 of 31 ) were mutant type in 2016, and the resistance frequency increased to $97.22 \%$ (70 of 72) in 2017. Only five isolates mutated in the $S d h B$ gene were detected, and all isolates had no mutation in the erg 27 gene. One isolate with quadruple-fungicide resistance $\left(\operatorname{Car}^{R} \operatorname{Die}^{R} \operatorname{Bos}^{R} \operatorname{Ipr}^{R} F^{S}{ }^{S}\right)$ was observed in this study.

The $\mathbf{E C}_{50}$ distribution of isolates with different genotypes in Hebei. In addition to molecular detection, mycelial growth assays were used to detect fungicide sensitivity. Because fenhexamid was not used in these regions, sensitivity toward it was not detected. Four more frequently used chemical fungicides were selected: namely carbendazim, diethofencarb, boscalid, and iprodione. The relationships between different genotypes and their $\mathrm{EC}_{50}$ distributions were analyzed (Fig. 1). As indicated in Table 8, the E198A, E198K, and E198V mutations were associated with high resistance, whereas one F200Y mutant was MR to carbendazim, with an $\mathrm{EC}_{50}$ value of $1.09 \mathrm{mg}$ per liter (Fig. 1A). The $\mathrm{EC}_{50}$ values of isolates with E198V mutations were in the range of 0.57 to $4.97 \mathrm{mg}$ per liter (Fig. 1B) and were MR or HR to diethofencarb. All isolates with

Table 2. Primers used in multiplex polymerase chain reaction (PCR)

\begin{tabular}{|c|c|c|c|c|}
\hline Gene & Primer name $^{\mathbf{a}}$ & Sequence $\left(5^{\prime} \rightarrow 3^{\prime}\right)$ & Primer concentration $(\mu M)$ & PCR product size (bp) \\
\hline \multirow[t]{2}{*}{ BenA } & BenA-F & GTCGTCCCATCGCCAAAGGT & 0.05 & 353 \\
\hline & BenA-R & ACGGTGACAGCACGGAAAGA & 0.05 & \\
\hline \multirow[t]{2}{*}{$S d h B$} & $S d h B-\mathrm{F}$ & ACACCGACCCAGCACCAGA & 0.4 & 428 \\
\hline & $S d h B-\mathrm{R}$ & TTAGCAATAACCGCCCAAA & 0.4 & \\
\hline \multirow[t]{2}{*}{ BcOS1 } & BcOS1-F & AGGTCACCCGCGTAGCAAGA & 0.2 & 223 \\
\hline & $B c O S 1-\mathrm{R}$ & TGCTTGATTTCACCCTTACA & 0.2 & \\
\hline \multirow[t]{2}{*}{ erg27 } & $\operatorname{erg} 27-\mathrm{F}$ & GCGTGGAGAACTCTAAATCGG & 0.2 & 191 \\
\hline & $\operatorname{erg} 27-\mathrm{R}$ & AGTGTAAGGCTTGATGGTATGC & 0.2 & \\
\hline
\end{tabular}

${ }^{\mathrm{a}} \mathrm{F}=$ forward, $\mathrm{R}=$ reverse

Table 3. Primers used in multiplex allele-specific primer extension polymerase chain reaction

\begin{tabular}{|c|c|c|}
\hline Gene & Primer name & Sequences $\left(5^{\prime} \rightarrow 3^{\prime}\right)^{\mathbf{a}}$ \\
\hline \multirow[t]{2}{*}{ BenA } & TAG-EAwt-F0 & САТСТTCATATCAATTCTCTTATTTTGGTTGAGAACTCTGACGA \\
\hline & TAG-EA-F0 & АCAATATACATCACTTAAACTTTCTTGGTTGAGAACTCTGACGC \\
\hline \multirow[t]{2}{*}{$S d h B$} & TAG-HYwt-R0 & 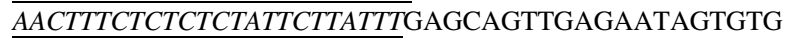 \\
\hline & TAG-HY-R0 & 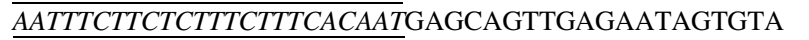 \\
\hline \multirow[t]{2}{*}{ BcOS1 } & TAG-ISwt-R0 & $\overline{\text { ATACTTTACAAACAAATAACACAC }}$ TGCCCTGGACGCCTTCGA \\
\hline & TAG-IS-R0 & 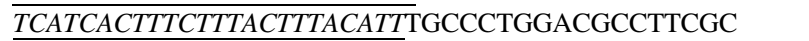 \\
\hline \multirow[t]{2}{*}{ erg27 } & TAG-FSwt-R0 & 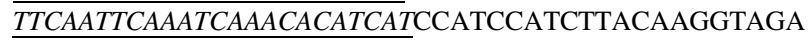 \\
\hline & TAG-FS-R0 & 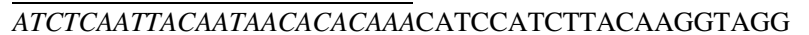 \\
\hline
\end{tabular}

${ }^{\mathrm{a}} \mathrm{TAG}$ sequences are indicated by underlining. 
E198K mutation showed high resistance to diethofencarb (Table 8). Mutant isolates with E198A and F200Y were diethofencarb sensitive (Die ${ }^{\mathrm{S}}$; Table 8). The $\mathrm{EC}_{50}$ values of five resistant isolates with H272R mutation in $S d h B$ ranged from 25.21 to $41.90 \mathrm{mg}$ per liter (Fig. 1C) and were determined as LR to boscalid (Table 8). $\mathrm{Ipr}^{\mathrm{R}}$ isolates with mutations at codons 365, 369, and 373 in $B c O S 1$ are shown in Figure 1D. We found a surprising result that one I365S mutant and one Q369P+N373S mutant were sensitive to iprodione. The $\mathrm{EC}_{50}$ values of other resistant isolates with $\mathrm{I} 365 \mathrm{~S}$ mutations ranged from 1.14 to $5.96 \mathrm{mg}$ per liter, and those with the Q369P+N373S mutation were mainly concentrated in the range of 1 to 3 and 4 to $6 \mathrm{mg}$ per liter. These isolates showed low resistance and moderate resistance to iprodione (Table 8). $\mathrm{Ipr}^{\mathrm{R}}$ isolates with $\mathrm{I} 365 \mathrm{~N}$ mutations were MR (Table 8), with $\mathrm{EC}_{50}$ values ranging from 3.40 to $7.38 \mathrm{mg}$ per liter (Fig. 1D).

Sensitivity change to carbendazim, diethofencarb, iprodione, and boscalid. We further compared the $\mathrm{EC}_{50}$ values of isolates col-

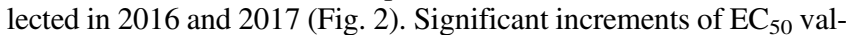
ues against carbendazim (Fig. 2A) and iprodione (Fig. 2D) and a decrease of $\mathrm{EC}_{50}$ values against diethofencarb (Fig. 2B) were observed from 2016 to 2017 in Hebei Province. Most isolates (95.15\%) were

Table 4. Median fluorescence intensity (MFI) values of 10 representative field isolates $^{\mathrm{a}}$

\begin{tabular}{lcccccrrr}
\hline Sample no. & BenA-E198 & BenA-198A & SdhB-H272 & SdhB-272Y & Bc OS1-I365 & BcOS1-365S & erg27-F412 & erg27-412S \\
\hline 1 & 45 & 24 & $\mathbf{2 1 0}$ & 18 & 42 & $\mathbf{3 9 7}$ & $\mathbf{9 9 8}$ & 45 \\
4 & $\mathbf{2 7 5}$ & 26 & $\mathbf{1 8 7}$ & 21 & $\mathbf{1 , 4 2 0}$ & 46 & $\mathbf{1 , 1 6 2}$ \\
8 & 30 & $\mathbf{3 2 2}$ & 20 & 28 & $\mathbf{9 5 3}$ & 37 & $\mathbf{7 7 7}$ \\
14 & 21 & 39 & $\mathbf{1 6 8}$ & 28 & 36 & $\mathbf{3 1 3}$ & $\mathbf{1 , 0 0 0}$ \\
15 & 27 & 16 & $\mathbf{3 3 7}$ & 21 & $\mathbf{1 , 8 3 2}$ & 42 & $\mathbf{1 , 4 9 4}$ \\
18 & 19 & 29 & $\mathbf{3 0 2}$ & 28 & $\mathbf{5 7 0}$ & 25 & $\mathbf{9 0 5}$ \\
23 & 32 & 33 & $\mathbf{2 5 3}$ & 29 & $\mathbf{1 , 3 5 1}$ & 35 & $\mathbf{1 , 1 6 4}$ \\
53 & $\mathbf{3 6 2}$ & 48 & $\mathbf{2 0 0}$ & 33 & $\mathbf{9 0 0}$ & 40 & 25 \\
74 & 46 & 43 & 24 & 25 & 32 & 53 & $\mathbf{8 3 2}$ & $\mathbf{2 , 0 0 6}$ \\
93 & $\mathbf{2 9 6}$ & 38 & 23 & 26 & 51 & 45 & $\mathbf{7 4 3}$ \\
$\mathrm{ddH}_{2} \mathrm{O}^{\text {b }}$ & 53 & 65 & 50 & 40 & 42 & 56 & 79 \\
\hline
\end{tabular}

a Positive MFI values over critical value are highlighted in bold.

b $\mathrm{ddH}_{2} \mathrm{O}=$ double-distilled $\mathrm{H}_{2} \mathrm{O}$.

Table 5. Comparison of the Bio-Plex suspension array and sequencing in 10 representative results

\begin{tabular}{|c|c|c|c|c|c|c|c|c|c|c|}
\hline \multirow[b]{2}{*}{ Sample no. } & \multicolumn{4}{|c|}{ Suspension array $^{a}$} & \multicolumn{6}{|c|}{ Sequencing } \\
\hline & BenA-198 & SdhB-272 & BcOS1-365 & erg27-412 & BenA-198 & BenA-200 & SdhB-272 & BcOS1-365 & $B c O S 1-369+373$ & $\operatorname{erg} 27-412$ \\
\hline 1 & E198\# & WT & $\mathrm{I} 365 \mathrm{~S}$ & WT & E198V & WT & WT & $\mathrm{I} 365 \mathrm{~S}$ & WT & WT \\
\hline 4 & WT & WT & WT & WT & WT & F200Y & WT & WT & $\mathrm{Q} 369 \mathrm{P}+\mathrm{N} 373 \mathrm{~S}$ & WT \\
\hline 8 & E198A & H272\# & WT & WT & E198A & WT & $\mathrm{H} 272 \mathrm{R}$ & WT & WT & WT \\
\hline 14 & E198\# & WT & $\mathrm{I} 365 \mathrm{~S}$ & WT & E198K & WT & WT & $\mathrm{I} 365 \mathrm{~S}$ & WT & WT \\
\hline 15 & E198\# & WT & WT & WT & E198K & WT & WT & WT & $\mathrm{Q} 369 \mathrm{P}+\mathrm{N} 373 \mathrm{~S}$ & WT \\
\hline 18 & E198\# & WT & WT & WT & E198V & WT & WT & WT & $\mathrm{Q} 369 \mathrm{P}+\mathrm{N} 373 \mathrm{~S}$ & WT \\
\hline 23 & E198\# & WT & WT & WT & E198V & WT & WT & WT & WT & WT \\
\hline 53 & E198A & WT & WT & WT & E198A & WT & WT & WT & $\mathrm{Q} 369 \mathrm{P}+\mathrm{N} 373 \mathrm{~S}$ & WT \\
\hline 74 & E198\# & H272\# & I365\# & WT & E198V & WT & $\mathrm{H} 272 \mathrm{R}$ & $\mathrm{I} 365 \mathrm{~N}$ & WT & WT \\
\hline 93 & E198A & H272\# & I365\# & WT & E198A & WT & $\mathrm{H} 272 \mathrm{R}$ & $\mathrm{I} 365 \mathrm{~N}$ & WT & WT \\
\hline
\end{tabular}

a The number sign "\#” indicates no calls; the Q369P mutations were always associated with N373S. WT = wild type.

Table 6. Resistance frequency of the isolates from the field using suspension array and sequencing

\begin{tabular}{|c|c|c|c|c|c|c|c|}
\hline \multirow[b]{2}{*}{ Gene } & \multirow[b]{2}{*}{ Codon } & \multicolumn{3}{|c|}{ Suspension array ${ }^{a}$} & \multicolumn{3}{|c|}{ Sequencing } \\
\hline & & Genotype & $\begin{array}{l}\text { Number of isolates } \\
\qquad(n=103)\end{array}$ & $\begin{array}{l}\text { Resistance frequency of } \\
\text { target codon }(\%)\end{array}$ & Genotype & $\begin{array}{l}\text { Number of isolates } \\
\qquad(n=103)\end{array}$ & $\begin{array}{l}\text { Resistance frequency of } \\
\text { target codon }(\%)\end{array}$ \\
\hline \multirow[t]{6}{*}{ BenA } & 198 & E198 & 1 & 99.03 & E198 & 1 & 99.03 \\
\hline & & E198A & 9 & & E198A & 9 & \\
\hline & & E198\# & 93 & & E198K & 9 & \\
\hline & & & & & E198V & 84 & \\
\hline & 200 & $-^{\mathrm{b}}$ & - & - & F200 & 102 & 0.97 \\
\hline & & - & - & - & F200Y & 1 & \\
\hline \multirow[t]{3}{*}{$S d h B$} & 272 & H272 & 98 & 4.85 & H272 & 98 & 4.85 \\
\hline & & $\mathrm{H} 272 \mathrm{Y}$ & 0 & & $\mathrm{H} 272 \mathrm{Y}$ & 0 & \\
\hline & & H272\# & 5 & & H272R & 5 & \\
\hline \multirow[t]{5}{*}{ BcOS1 } & 365 & I365 & 81 & 21.36 & I365 & 81 & 21.36 \\
\hline & & I365S & 17 & & I365S & 17 & \\
\hline & & I365\# & 5 & & $\mathrm{I} 365 \mathrm{~N}$ & 5 & \\
\hline & $369+373$ & - & - & - & $\mathrm{Q} 369+\mathrm{N} 373$ & 47 & 54.37 \\
\hline & & - & - & - & $\mathrm{Q} 369 \mathrm{P}+\mathrm{N} 373 \mathrm{~S}$ & 56 & \\
\hline \multirow[t]{2}{*}{ erg27 } & 412 & F412 & 103 & 0.00 & F412 & 103 & 0.00 \\
\hline & & F412S & 0 & & F412S & 0 & \\
\hline
\end{tabular}

${ }^{a}$ Four genotypes within detection range in suspension array were presented.

$\mathrm{b}$ " - ." indicated other codons outside the detection range in the suspension array. 
sensitive to boscalid with $\mathrm{EC}_{50}$ values ranging from 1.88 to $9.83 \mathrm{mg}$ per liter, and only five isolates showed LR to boscalid. No significant change was observed in 2 years (Fig. 2C). The $\mathrm{EC}_{50}$ values of $\mathrm{Ipr}^{\mathrm{R}}$ isolates were 0.02 to $3.45 \mathrm{mg}$ per liter in 2016 and ranged from 0.11 to $7.38 \mathrm{mg}$ per liter in 2017 (Fig. 2D). The resistance frequencies to carbendazim, diethofencarb, iprodione, and boscalid were 100, 87.10, 3.23 , and $61.29 \%$ in $2016(n=31)$ and $100,91.67,5.56$, and $97.22 \%$ in $2017(n=72)$, respectively. These results indicate that the problem of multiple resistance to carbendazim, diethofencarb, iprodione, and boscalid is serious in Hebei Province.

The $\mathrm{EC}_{50}$ variation of the isolates with different genotypes was further analyzed (Fig. 3). For carbendazim, the increment in fungicide resistance in Hebei (Fig. 2A) was attributed to the increments of $\mathrm{EC}_{50}$ values with BenA-E198V and BenA-E198K mutations (Fig. 3A). The change of $\mathrm{EC}_{50}$ in response to diethofencarb in different genotypes from 2016 to 2017 was not observed (Fig. 2B). The cause for the decrease in $\mathrm{EC}_{50}$ distribution to diethofencarb in Hebei (Fig. 2B) was that the $\mathrm{EC}_{50}$ values for BenA-E198K mutants were far greater than for BenA-E198V mutants, and the the proportion of isolates that carried BenA-E198K to BenA-E198V reduced from 2016 to 2017 (Fig. 3B). The isolates that possessed BcOS1-I365S and $B c O S 1-\mathrm{Q} 369 \mathrm{P}+\mathrm{N} 373 \mathrm{~S}$ mutations had increased $\mathrm{EC}_{50}$ values. A new genotype of I365N with MR appeared in 2017 (Fig. 3C). These results accounted for the increment of iprodione $\mathrm{EC}_{50}$ values from 2016 to 2017 (Fig. 2D).

\section{Discussion}

The development of $B$. cinerea multiple resistance to different classes of fungicides was reported previously (Bardas et al. 2010). Considering the large numbers of isolates that are resistant to a variety of fungicides, conventional methods have proved insufficient to provide adequate detection (Banno et al. 2008; Leroux et al. 2010; Van der Heyden et al. 2014). Our research group successfully developed a multiplex microbead-based suspension array for the simultaneous detection of eight alleles of four resistance genes using the BioPlex 200 platform (Zhang et al. 2016). The results of eight genotypes detected by suspension array were completely consistent with sequencing. The suspension array provides a high-throughput and high-efficiency method for molecular detection of fungicide resistance in field isolates.

In our study, the suspension array could detect the mutations at codon 198 in BenA except for the F200Y mutation, which was out of the detected range of this method. The percentage of isolates that mutated at codon 198 was $99.03 \%$ in Hebei Province. Previous studies also revealed that the mutations in codon 198 appeared more frequently (Luck and Gillings 1995; Ziogas et al. 2009). Therefore, the suspension array results are sufficient to detect the $B$. cinerea strains that are resistant to carbendazim and can finally guide carbendazim application in the field.
$\mathrm{Ipr}^{\mathrm{R}}$ isolates detected in Hebei Province possessed point mutations at codons 365, 369, and 373 in BcOS1. The I365S and Q369P+ N373S mutant strains accounted for the majority. Previous studies also found that mutations in the $B c O S 1$ gene associated with dicarboximide resistance are diverse in B. cinerea (Grabke et al. 2014; $\mathrm{Ma}$ et al. 2007). Considering the limitations of the detection scope in this article, further optimization of the suspension array method is required to cover a wider range, such as adding Q369P and N373S genotype detection in the BcOS1 gene.

Isolates of $B$. cinerea resistant to benzimidazole fungicides were reported frequently in previous studies (Fan et al. 2017; Leroux et al. 2002; Liu et al. 2016). All isolates tested in this study were HR to carbendazim. Most of the isolates carried the E198V mutation in BenA $(81.55 \%)$, which had a relatively low $\mathrm{EC}_{50}$ for diethofencarb. The proportion of E198K mutants that were HR to diethofencarb was low (8.74\%). Therefore, although the resistance frequency to diethofencarb was high, the average $\mathrm{EC}_{50}$ was relatively low (6.01 mg per liter). Similarly, isolates had a HR frequency, but were LR or MR to iprodione. The I365S mutant with HR was not observed, which was reported in a previous study (Grabke et al. 2014). Increasing the dose of diethofencarb or iprodione might be useful to inhibit these resistant isolates mutated in $B e n A$ or $B c O S 1$. Because $B$. cinerea was considered as a high-risk pathogen for the development

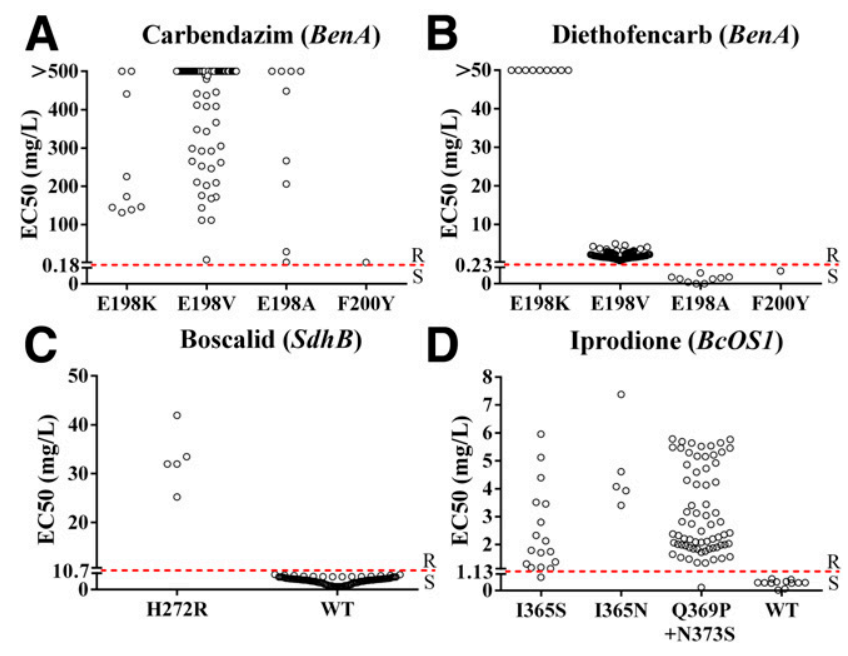

Fig. 1. Frequency distribution of half maximal effective concentration $\left(E_{50}\right)$ values for A, carbendazim, B, diethofencarb, C, boscalid, and D, iprodione. Data in the $>500$ position indicate that the $\mathrm{EC}_{50}$ values for carbendazim were more than $500 \mathrm{mg}$ per liter. Data in the $>50$ position indicate that the $\mathrm{EC}_{50}$ values for diethofencarb were more than $50 \mathrm{mg}$ per liter. The red dotted line represents 5 times the sensitivity baseline. $R=$ resistance isolate, $S=$ sensitive isolate, and $W T=$ wild type.

Table 7. Different genotype of Botrytis cinerea

\begin{tabular}{|c|c|c|c|c|c|c|c|}
\hline \multirow[b]{2}{*}{ Multiple resistance } & \multirow[b]{2}{*}{ Type } & \multicolumn{4}{|c|}{ Genotype } & \multicolumn{2}{|c|}{ Number of isolates } \\
\hline & & BenA & $S d h B$ & Bos1 & erg27 & $2016(n=31)$ & $2017(n=72)$ \\
\hline Single & Type I $\left(\mathrm{Car}^{\mathrm{R}} \mathrm{Die}^{\mathrm{S}} \mathrm{Bos}^{\mathrm{S}} \mathrm{Ipr}^{\mathrm{S}} \mathrm{Fen}^{\mathrm{S}}\right)^{\mathrm{a}}$ & E198A & $\mathrm{WT}^{\mathrm{b}}$ & WT & WT & 2 & 0 \\
\hline \multirow[t]{6}{*}{ Dual } & Type II $\left(\mathrm{Car}^{\mathrm{R}} \mathrm{Die}^{\mathrm{S}} \mathrm{Bos}^{\mathrm{R}} \operatorname{Ipr}^{\mathrm{S}} \mathrm{Fen}^{\mathrm{S}}\right)$ & E198A & $\mathrm{H} 272 \mathrm{R}$ & WT & WT & 1 & 0 \\
\hline & Type III $\left(\mathrm{Car}^{\mathrm{R}} \mathrm{Die}^{\mathrm{S}} \mathrm{Bos}^{\mathrm{S}} \mathrm{Ipr}^{\mathrm{R}} \mathrm{Fen}^{\mathrm{S}}\right)$ & E198A & WT & $\mathrm{I} 365 \mathrm{~S}$ & WT & 0 & 1 \\
\hline & Type IV $\left(\mathrm{Car}^{\mathrm{R}} \operatorname{Die}^{\mathrm{S}} \operatorname{Bos}^{\mathrm{S}} \operatorname{Ipr}^{\mathrm{R}} \mathrm{Fen}^{\mathrm{S}}\right)$ & E198A & WT & $\mathrm{I} 365 \mathrm{~N}$ & WT & 0 & 1 \\
\hline & Type V $\left(\mathrm{Car}^{\mathrm{R}} \mathrm{Die}^{\mathrm{S}} \mathrm{Bos}^{\mathrm{S}} \operatorname{Ipr}^{\mathrm{R}} \mathrm{Fen}^{\mathrm{S}}\right)$ & E198A & WT & $\mathrm{Q} 369 \mathrm{P}+\mathrm{N} 373 \mathrm{~S}$ & WT & 0 & 1 \\
\hline & Type VI $\left(\mathrm{Car}^{\mathrm{R}} \mathrm{Die}^{\mathrm{R}} \operatorname{Bos}^{\mathrm{S}}{ }^{\mathrm{I}}{ }^{\mathrm{S}} \mathrm{Fen}^{\mathrm{S}}\right)$ & E198V & WT & WT & WT & 7 & 2 \\
\hline & Type VII $\left(\mathrm{Car}^{\mathrm{R}} \mathrm{Die}^{\mathrm{S}} \mathrm{Bos}^{\mathrm{S}} \mathrm{Ipr}^{\mathrm{R}} \mathrm{Fen}^{\mathrm{S}}\right)$ & $\mathrm{F} 200 \mathrm{Y}$ & WT & $\mathrm{Q} 369 \mathrm{P}+\mathrm{N} 373 \mathrm{~S}$ & WT & 1 & 0 \\
\hline \multirow[t]{5}{*}{ Triple } & Type VIII (Car $\left.{ }^{R} \operatorname{Die}^{S} \operatorname{Bos}^{R} \operatorname{Ipr}^{R} F^{2}{ }^{S}\right)$ & E198A & $\mathrm{H} 272 \mathrm{R}$ & $\mathrm{I} 365 \mathrm{~N}$ & WT & 0 & 3 \\
\hline & Type IX $\left(\mathrm{Car}^{\mathrm{R}} \mathrm{Die}^{\mathrm{R}} \mathrm{Bos}^{\mathrm{S}} \operatorname{Ipr}^{\mathrm{R}} \mathrm{Fen}^{\mathrm{S}}\right)$ & E198V & WT & $\mathrm{I} 365 \mathrm{~S}$ & WT & 8 & 7 \\
\hline & Type X $\left(\mathrm{Car}^{\mathrm{R}} \mathrm{Die}^{\mathrm{R}} \mathrm{Bos}^{\mathrm{S}} \mathrm{Ipr}^{\mathrm{R}} \mathrm{Fen}^{\mathrm{S}}\right)$ & E198V & WT & $\mathrm{Q} 369 \mathrm{P}+\mathrm{N} 373 \mathrm{~S}$ & WT & 6 & 53 \\
\hline & Type XI $\left(\mathrm{Car}^{\mathrm{R}} \mathrm{Die}^{\mathrm{R}} \mathrm{Bos}^{\mathrm{S}} \operatorname{Ipr}^{\mathrm{R}} \mathrm{Fen}^{\mathrm{S}}\right)$ & E198K & WT & $\mathrm{I} 365 \mathrm{~S}$ & WT & 1 & 0 \\
\hline & Type XII $\left(\mathrm{Car}^{\mathrm{R}} \mathrm{Die}^{\mathrm{R}} \mathrm{Bos}^{\mathrm{S}} \mathrm{Ipr}^{\mathrm{R}} \mathrm{Fen}{ }^{\mathrm{S}}\right)$ & E198K & WT & $\mathrm{Q} 369 \mathrm{P}+\mathrm{N} 373 \mathrm{~S}$ & WT & 5 & 3 \\
\hline Quadruple & Type XIII $\left(\mathrm{Car}^{\mathrm{R}} \mathrm{Die}^{\mathrm{R}} \mathrm{Bos}^{\mathrm{R}} \mathrm{Ipr}^{\mathrm{R}} \mathrm{Fen}^{\mathrm{S}}\right)$ & E198V & $\mathrm{H} 272 \mathrm{R}$ & $\mathrm{I} 365 \mathrm{~N}$ & WT & 0 & 1 \\
\hline
\end{tabular}

${ }^{a}$ Superscript letters R and S indicate resistance and sensitivity, respectively. Car $=$ carbendazim, Die $=$ diethofencarb, Bos $=$ boscalid, Ipr $=$ iprodione, Fen $=$ fenhexamid.

${ }^{\mathrm{b}} \mathrm{WT}=$ wild type 
of boscalid (Fan et al. 2017), the appearance of five H272R mutants indicated that boscalid should be used circumspectly in the future. According to these results, carbendazim is thus not recommended for controlling gray mold in Hebei Province in China. The application of diethofencarb, iprodione, and boscalid should be prudent. Rather, fenhexamid is suggested.

A high frequency of isolates with multiple resistance was observed in this study $(98.06 \%)$. One isolate with quadruple resistance emerged in Hebei Province. Attention should be paid to prevent its spread under fungicide selection. Occurrence of multiple resistance was common in Botrytis isolates (Lu et al. 2016). The overuse of fungicides against $\mathrm{Bo}$ trytis might result in poorer control of gray mold (Rupp et al. 2017). The frequency of multiple resistance strains increased, which was driven by the continuous use of fungicides (Kretschmer et al. 2009). Therefore, multiple-fungicide resistance should be monitored often to track the resistance statue of $B$. cinerea in the field. The suspension array can satisfy the requirements of multiple-resistance detection and achieve the purpose of early warning.

We found that one genotype corresponds to one or more resistance levels through the combination of conventional and molecular methods, which is consistent with previous studies (Grabke et al. 2014; Yin et al. 2011). We discovered that the level of resistance increased under the sustained fungicide application, even the strains carried the same mutation. Previous studies also reported that not only the resistance frequency but also the resistance level increased with continuous use of fungicides (Jia 2017). Molecular methods have been widely used in the study of fungicide resistance to detect the genotype of isolates (Banno et al. 2008; De Miccolis Angelini et al. 2014a; Fernández-Ortuño et al. 2012). Molecular methods can provide information about the number of resistant isolates in the field. Resistance frequency, rather than resistance level, could be obtained by molecular methods. Traditional methods could be used to guide the application dose of fungicides. Therefore, the combination of two types of methods could more accurately reflect the resistance status in the field.

In this study, we also observed that two isolates harboring the I365S or Q369P+N373S mutation did not exhibit resistance to iprodione when tested by the mycelial growth assay. This might be attributable to the presence of heterokaryon, which may have multiple nuclei (Büttner et al. 1994; Faretra and Pollastro 1993). However, further research is needed to elucidate this observation.

Table 8. The number of isolates of $B$. cinerea in different genotypes corresponding to different resistance levels

\begin{tabular}{|c|c|c|c|c|c|c|c|c|c|c|c|c|c|c|}
\hline \multirow[b]{2}{*}{$\begin{array}{l}\text { Resistance } \\
\text { level }\end{array}$} & \multicolumn{4}{|c|}{ Carbendazim } & \multicolumn{4}{|c|}{ Diethofencarb } & \multicolumn{2}{|c|}{ Boscalid } & \multicolumn{4}{|c|}{ Iprodione } \\
\hline & E198K & E198V & E198A & F200Y & E198K & E198V & E198A & F200Y & H272R & WT & I365N & I365S & $\begin{array}{c}\text { Q369P+ } \\
\text { N373S }\end{array}$ & $\mathbf{W T}^{\mathbf{a}}$ \\
\hline Sensitive & 0 & 0 & 0 & 0 & 0 & 0 & 9 & 1 & 0 & 98 & 0 & 1 & 1 & 12 \\
\hline Low & 0 & 0 & 0 & 0 & 0 & 0 & 0 & 0 & 5 & 0 & 0 & 9 & 29 & 0 \\
\hline Moderate & 0 & 0 & 0 & 1 & 0 & 47 & 0 & 0 & 0 & 0 & 5 & 7 & 39 & 0 \\
\hline High & 9 & 84 & 9 & 0 & 9 & 37 & 0 & 0 & 0 & 0 & 0 & 0 & 0 & 0 \\
\hline
\end{tabular}

${ }^{\mathrm{a}} \mathrm{WT}=$ wild type.
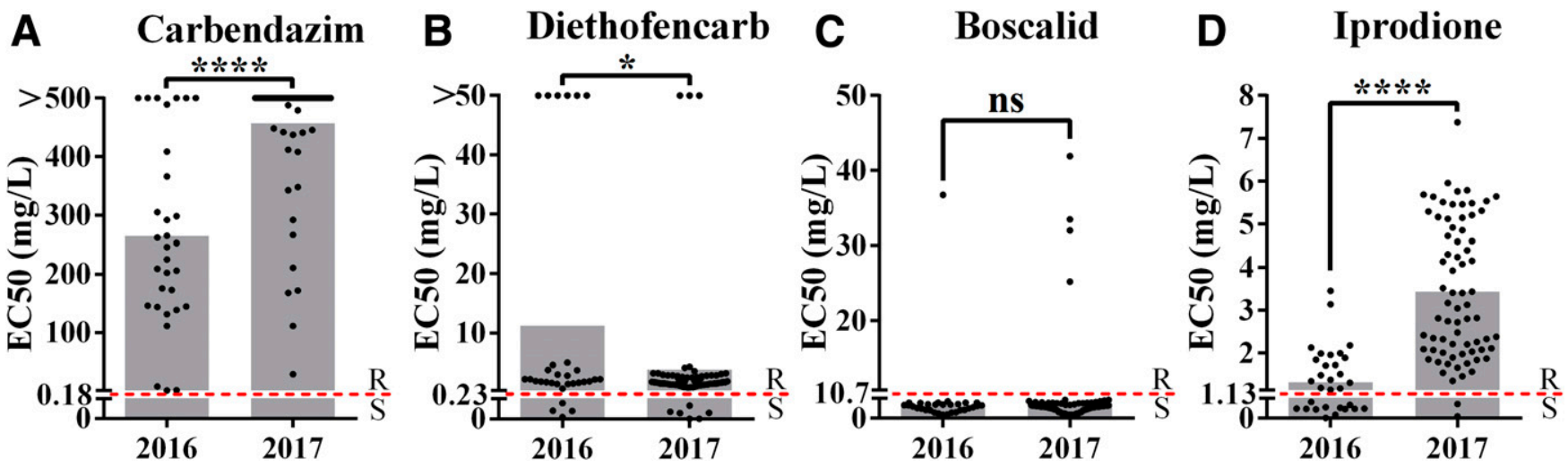

Fig. 2. Changes in half maximal effective concentration $\left(E_{50}\right)$ values for $\mathbf{A}$, carbendazim, $\mathbf{B}$, diethofencarb, $\mathbf{C}$, boscalid, and $\mathbf{D}$, iprodione in Hebei between 2016 and 2017 . The red dotted line represents 5 times the sensitivity baseline. ${ }^{*} P<0.05,{ }^{* * *} P<0.0001(n=103) . R=$ resistance isolate, $S=$ sensitive isolate, and ns $=$ no significant difference.
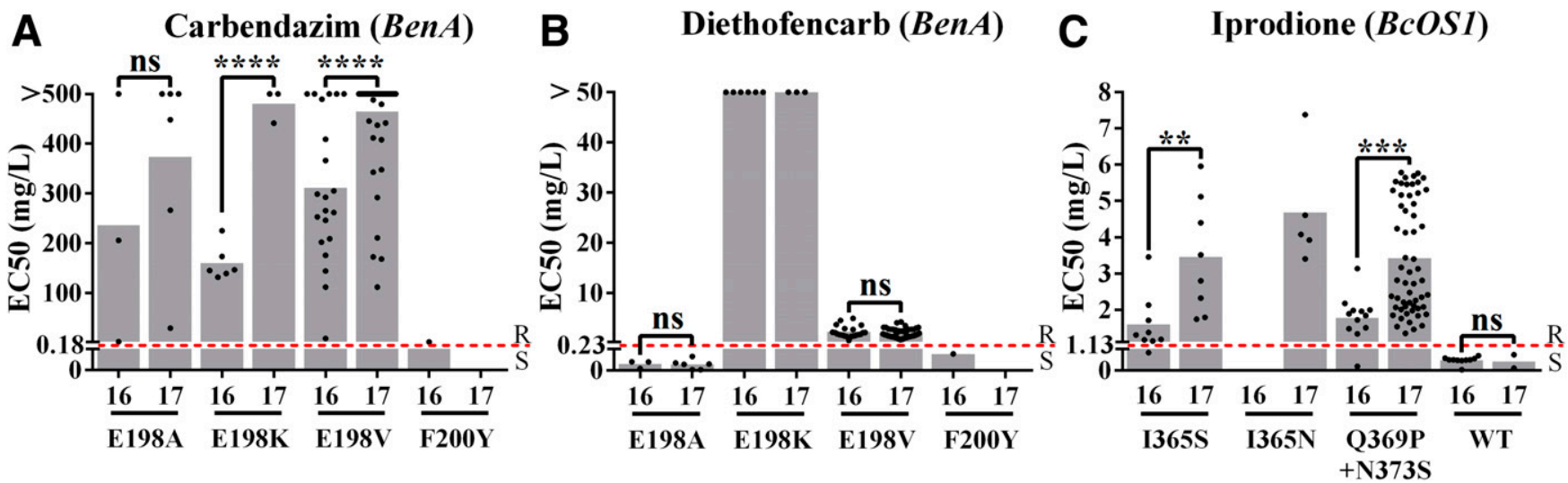

Fig. 3. Change trend of half maximal effective concentration $\left(E C_{50}\right)$ values for $\mathbf{A}$, carbendazim, $\mathbf{B}$, diethofencarb, and $\mathbf{C}$, iprodione in Hebei from 2016 to 2017 . ${ }^{* \star} P<0.01$, ${ }^{* \star *} P<$ $0.001,{ }^{* * * *} P<0.0001$. The red dotted line represents 5 times the sensitivity baseline. $n s=$ no significant difference, $R=$ resistance isolate, $S=$ sensitive isolate, and WT $=$ wild type. 
In summary, the molecular method of a suspension array can greatly simplify and speed up the process of multiple-resistance detection in field populations. Although the detection range needs to be further explored, the suspension array is recommended to first identify the resistance frequency and genotypes in large quantities of phytopathogen, which can achieve the goal of early warning, followed by the utilization of traditional methods to determine the fungicide sensitivity for the mutant isolates. Via this combination, more efficient and accurate results about multiple resistance of $B$. cinerea in the region could be obtained, so that fields could receive suitable fungicide treatments against $B$. cinerea, including the right fungicide types and fungicide dose.

\section{Acknowledgments}

We thank LetPub (www.letpub.com) for providing linguistic assistance during the preparation of this manuscript.

\section{Literature Cited}

Banno, S., Fukumori, F., Ichiishi, A., Okada, K., Uekusa, H., Kimura, M., and Fujimura, M. 2008. Genotyping of benzimidazole-resistant and dicarboximideresistant mutations in Botrytis cinerea using real-time polymerase chain reaction assays. Phytopathology 98:397-404.

Bardas, G. A., Veloukas, T., Koutita, O., and Karaoglanidis, G. S. 2010. Multiple resistance of Botrytis cinerea from kiwifruit to SDHIs, QoIs and fungicides of other chemical groups. Pest Manag. Sci. 66:967-973.

Bartlett, D. W., Clough, J. M., Godwin, J. R., Hall, A. A., Hamer, M., and ParrDobrzanski, B. 2002. The strobilurin fungicides. Pest Manag. Sci. 58:649-662.

Beever, R. E., Laracy, E. P., and Pak, H. A. 1989. Strains of Botrytis cinerea resistant to dicarboximide and benzimidazole fungicides in New Zealand vineyards. Plant Pathol. 38:427-437.

Billard, A., Laval, V., Fillinger, S., Leroux, P., Lachaise, H., Beffa, R., and Debieu, D. 2012. The allele-specific probe and primer amplification assay, a new realtime PCR method for fine quantification of single-nucleotide polymorphisms in pooled DNA. Appl. Environ. Microbiol. 78:1063-1068.

Büttner, P., Koch, F., Voigt, K., Quidde, T., Risch, S., Blaich, R., Brückner, B., and Tudzynski, P. 1994. Variations in ploidy among isolates of Botrytis cinerea: Implications for genetic and molecular analyses. Curr. Genet. 25:445-450.

Chatzidimopoulos, M., Ganopoulos, I., Vellios, E., Madesis, P., Tsaftaris, A., and Pappas, A. C. 2014. Development of a two-step high-resolution melting (HRM) analysis for screening sequence variants associated with resistance to the QoIs, benzimidazoles and dicarboximides in airborne inoculum of Botrytis cinerea. FEMS Microbiol. Lett. 360:126-131.

Cui, W., Beever, R. E., Parkes, S. L., and Templeton, M. D. 2004. Evolution of an osmosensing histidine kinase in field strains of Botryotinia fuckeliana (Botrytis cinerea) in response to dicarboximide fungicide usage. Phytopathology 94 : 1129-1135.

Cui, W., Beever, R. E., Parkes, S. L., Weeds, P. L., and Templeton, M. D. 2002. An osmosensing histidine kinase mediates dicarboximide fungicide resistance in Botryotinia fuckeliana (Botrytis cinerea). Fungal Genet. Biol. 36:187-198.

De Miccolis Angelini, R. M., Masiello, M., Rotolo, C., Pollastro, S., and Faretra, F. 2014a. Molecular characterisation and detection of resistance to succinate dehydrogenase inhibitor fungicides in Botryotinia fuckeliana (Botrytis cinerea). Pest Manag. Sci. 70:1884-1893.

De Miccolis Angelini, R. M., Rotolo, C., Masiello, M., Gerin, D., Pollastro, S., and Faretra, F. 2014b. Occurrence of fungicide resistance in populations of Botryotinia fuckeliana (Botrytis cinerea) on table grape and strawberry in southern Italy. Pest Manag. Sci. 70:1785-1796.

De Miccolis Angelini, R. M., Rotolo, C., Masiello, M., Pollastro, S., Ishii, H., and Faretra, F. 2012. Genetic analysis and molecular characterisation of laboratory and field mutants of Botryotinia fuckeliana (Botrytis cinerea) resistant to QoI fungicides. Pest Manag. Sci. 68:1231-1240.

Debieu, D., Bach, J., Montesinos, E., Fillinger, S., and Leroux, P. 2013. Role of sterol 3-ketoreductase sensitivity in susceptibility to the fungicide fenhexamid in Botrytis cinerea and other phytopathogenic fungi. Pest Manag. Sci. 69: 642-651

Fan, F., Hamada, M. S., Li, N., Li, G. Q., and Luo, C. X. 2017. Multiple fungicide resistance in Botrytis cinerea from greenhouse strawberries in Hubei Province, China. Plant Dis. 101:601-606.

Faretra, F., and Pollastro, S. 1993. Genetics of sexual compatibility and resistance to benzimidazole and dicarboximide fungicides in isolates of Botryotinia fuckeliana (Botrytis cinerea) from nine countries. Plant Pathol. 42:48-57.

Fernández-Ortuño, D., Chen, F., and Schnabel, G. 2012. Resistance to pyraclostrobin and boscalid in Botrytis cinerea isolates from strawberry fields in the Carolinas. Plant Dis. 96:1198-1203.

Fillinger, S., Ajouz, S., Nicot, P. C., Leroux, P., and Bardin, M. 2012. Functional and structural comparison of pyrrolnitrin- and iprodione-induced modifications in the class III histidine-kinase Bos1 of Botrytis cinerea. PLoS One 7:e42520.

Grabke, A., Fernandez-Ortuno, D., Amiri, A., Li, X., Peres, N. A., Smith, P., and Schnabel, G. 2014. Characterization of iprodione resistance in Botrytis cinerea from strawberry and blackberry. Phytopathology 104:396-402.
Ishii, H., Fountaine, J., Chung, W. H., Kansako, M., Nishimura, K., Takahashi, K. and Oshima, M. 2009. Characterisation of QoI-resistant field isolates of Botrytis cinerea from citrus and strawberry. Pest Manag. Sci. 65:916-922.

Jia, Z. S. 2017. The Role of Fungicide Spray Coverage and Population Heterogeneity on the Selection for Fungicide Resistance in Botrytis squamosal. Master's dissertation, McGill University, Montreal, Quebec, Canada.

Jiang, J., Ding, L., Michailides, T. J., Li, H., and Ma, Z. 2009. Molecular characterization of field azoxystrobin-resistant isolates of Botrytis cinerea Pestic. Biochem. Physiol. 93:72-76.

Kretschmer, M., Leroch, M., Mosbach, A., Walker, A. S., Fillinger, S., Mernke, D., Schoonbeek, H. J., Pradier, J. M., Leroux, P., De Waard, M. A., and Hahn, M. 2009. Fungicide-driven evolution and molecular basis of multidrug resistance in field populations of the grey mould fungus Botrytis cinerea. PLoS Pathog 5:e1000696.

Latorre, B. A., Spadaro, I., and Rioja, M. E. 2002. Occurrence of resistant strains of Botrytis cinerea to anilinopyrimidine fungicides in table grapes in Chile. Crop Prot. 21:957-961.

Leroch, M., Plesken, C., Weber, R. W., Kauff, F., Scalliet, G., and Hahn, M. 2013 Gray mold populations in german strawberry fields are resistant to multiple fungicides and dominated by a novel clade closely related to Botrytis cinerea. Appl. Environ. Microbiol. 79:159-167.

Leroux, P., Fritz, R., Debieu, D., Albertini, C., Lanen, C., Bach, J., Gredt, M., and Chapeland, F. 2002. Mechanisms of resistance to fungicides in field strains of Botrytis cinerea. Pest Manag. Sci. 58:876-888.

Leroux, P., Gredt, M., Leroch, M., and Walker, A. S. 2010. Exploring mechanisms of resistance to respiratory inhibitors in field strains of Botrytis cinerea, the causal agent of gray mold. Appl. Environ. Microbiol. 76:6615-6630.

Liu, S., Che, Z., and Chen, G. 2016. Multiple-fungicide resistance to carbendazim, diethofencarb, procymidone, and pyrimethanil in field isolates of Botrytis cinerea from tomato in Henan Province, China. Crop Prot. 84:56-61.

Lu, X. H., Jiao, X. L., Hao, J. J., Chen, A. J., and Gao, W. W. 2016. Characterization of resistance to multiple fungicides in Botrytis cinerea populations from Asian ginseng in northeastern China. Eur. J. Plant Pathol. 144:467-476

Luck, J. E., and Gillings, M. R. 1995. Rapid identification of benomyl resistant strains of Botrytis cinerea using the polymerase chain reaction. Mycol. Res. 99:1483-1488.

Ma, Z., Yan, L., Luo, Y., and Michailides, T. J. 2007. Sequence variation in the two-component histidine kinase gene of Botrytis cinerea associated with resistance to dicarboximide fungicides. Pestic. Biochem. Physiol. 88 300-306.

Muñoz, C., Gómez, T. S., and Volpe, M. L. 2009. Tetra primer ARMS-PCR for identification of SNP in beta-tubulin of Botrytis cinerea, responsible of resistance to benzimidazole. J. Microbiol. Methods 78:245-246.

Oshima, M., Banno, S., Okada, K., Takeuchi, T., Kimura, M., Ichiishi, A., Yamaguchi, I., and Fujimura, M. 2006. Survey of mutations of a histidine kinase gene $B c O S 1$ in dicarboximide-resistant field isolates of Botrytis cinerea. J. Gen. Plant Pathol. 72:65-73.

Rupp, S., Weber, R. W., Rieger, D., Detzel, P., and Hahn, M. 2017. Spread of Botrytis cinerea strains with multiple fungicide resistance in German horticulture. Front. Microbiol. 7:2075.

Saito, S., Michailides, T. J., and Xiao, C. L. 2016. Fungicide resistance profiling in Botrytis cinerea populations from blueberry in California and Washington and their impact on control of gray mold. Plant Dis. 100:2087-2093.

Van der Heyden, H., Dutilleul, P., Brodeur, L., and Carisse, O. 2014. Spatial distribution of single-nucleotide polymorphisms related to fungicide resistance and implications for sampling. Phytopathology 104:604-613.

Veloukas, T., Leroch, M., Hahn, M., and Karaoglanidis, G. S. 2011. Detection and molecular characterization of boscalid-resistant Botrytis cinerea isolates from strawberry. Plant Dis. 95:1302-1307.

Yarden, O., and Katan, T. 1993. Mutations leading to substitutions at amino acids 198 and 200 of beta-tubulin that correlate with benomyl-resistance phenotypes of field strains of Botrytis cinerea. Phytopathology 83:1478-1483.

Yin, Y. N., Kim, Y. K., and Xiao, C. L. 2011. Molecular characterization of boscalid resistance in field isolates of Botrytis cinerea from apple. Phytopathology 101:986-995.

Yin, Y. N., Kim, Y. K., and Xiao, C. L. 2012. Molecular characterization of pyraclostrobin resistance and structural diversity of the cytochrome b gene in Botrytis cinerea from apple. Phytopathology 102:315-322.

Yoshimi, A., Kojima, K., Takano, Y., and Tanaka, C. 2005. Group III histidine kinase is a positive regulator of Hog1-type mitogen-activated protein kinase in filamentous fungi. Eukaryot. Cell 4:1820-1828.

Yourman, L. F., Jeffers, S. N., and Dean, R. A. 2000. Genetic analysis of isolates of Botrytis cinerea sensitive and resistant to benzimidazole and dicarboximide fungicides. Phytopathology 90:851-859.

Zhang, X., Xie, F., Lv, B., Zhao, P., and Ma, X. 2016. Suspension array for multiplex detection of eight fungicide-resistance related alleles in Botrytis cinerea. Front. Microbiol. 7:1482.

Ziogas, B. N., Nikou, D., Markoglou, A. N., Malandrakis, A. A., and Vontas, J. 2009. Identification of a novel point mutation in the $\beta$-tubulin gene of Botrytis cinerea and detection of benzimidazole resistance by a diagnostic PCR-RFLP assay. Eur. J. Plant Pathol. 125:97-107. 